\title{
Democracia sem garantias ${ }^{1}$
}

\author{
Marc James Léger (Pesquisador independente, Montreal, Canadá) *
}

Tradução:

Rafael Melo (Universidade Federal Fluminense, Brasil) **

Caroline Alciones de Oliveira Leite (Universidade Federal do Rio de Janeiro, Brasil) ${ }^{* * *}$

Luiz Sérgio de Oliveira (Universidade Federal Fluminense, Brasil) ${ }^{* * * *}$

https://doi.org/10.22409/poiesis.v21i36.43173

RESUMO: Com uma observação aguda das crises postas para a democracia na contemporaneidade, atravessada e engolfada pela expansão e pela onipresença das ideologias neoliberais, Marc James Léger é categórico ao afirmar que a democracia está em apuros. Em sua análise, o autor apresenta a compreensão de que, há muito, os movimentos da arte, independentemente de suas conceitualizações e perspectivas, nunca estiveram dissociados do capitalismo e da ideologia burguesa, que sempre lhes serviram como pano de fundo. Mais inquietante, entretanto, é a formulação de Léger ao se perguntar e ao nos perguntar "se a arte de alguma forma não é, involuntária ou programaticamente, um aspecto dessa mesma governança neoliberal". (Resumo e palavras-chave elaborados pelos editores desta edição)

PALAVRAS-CHAVE: democracia; crise; política; arte 
* Pesquisador independente com residência em Montreal, Canadá, Marc James Léger é o editor de The Idea of the Avant Garde - And What It Means Today, volumes 1 and 2 (2014, 2019) e o autor de Don't Network: The Avant Garde After Networks (Minor Compositions, 2018), Drive in Cinema: Essays on Film, Theory and Politics (Intellect, 2015), The Neoliberal Undead (Zero Books, 2013), Brave New Avant Garde (Zero Books, 2012) e Vanguardia: Socially Engaged Art and Theory (Manchester University Press, 2009). Léger vem trabalhando em um novo livro a ser lançado em breve: Too Black to Fail: The Obama Portraits and the Politics of Post-Representation. E-mail: leger.mj@gmail.com

** Rafael Melo é graduado em Artes pela Universidade Federal Fluminense, Niterói. E-mail: rcmelo97@gmail .com. Orcid: https://orcid. org/0000-0002-1614-7205

*** Caroline Alciones de Oliveira Leite é doutoranda do Programa de Pós-Graduação em Artes Visuais da Escola de Belas Artes da UFRJ. Email: alcionesdol@gmail.com Orcid: https://orcid.org/0000-00027866-7863

**** Luiz Sérgio de Oliveira é artista e professor titular da Universidade Federal Fluminense, doutor em Artes Visuais pelo PPGAV-EBAUFRJ, mestre em Arte pela Universidade de Nova York E-mail: luizsergiodeoliveira.br@gmail.com. Orcid: https://orcid.org/00000002-8616-5089

Citação recomendada:

LEGER, Marc James. Democracia sem garantias. (tradução: Rafael Melo, Caroline Alciones de Oliveira Leite, Luiz Sérgio de Oliveira). Revista Poiésis, Niterói, v. 21, n. 36, p. 209-222, jul./dez. 2020. [https://doi.org/10.22409/poiesis.v21i36.43173]

(cc) BY-NC-ND Atribuição-NãoComercial 4.0 Internacional (CC-BY-NC) (c) 2020 Marc James Léger 


\section{Democracia sem garantias}

Eventos recentes revelam que a democracia está em sérios apuros. A governança neoliberal que acompanhou a globalização, o pós-fordismo e a nova economia digital tem resultado em consequências desastrosas, que incluem um retorno aos níveis de desigualdade econômica do século XIX, catástrofes ambientais sem precedentes e regimes de segurança em estado de emergência produzidos por intermináveis guerras por mudanças de regime. Quando se considera a relação da cultura com a sociedade, pode-se perguntar se a arte também está em apuros ou, de uma maneira talvez mais cética, se a arte de alguma forma não é, involuntária ou programaticamente, um aspecto dessa mesma governança neoliberal.
Em sua versão iluminista moderna, pensava-se que a arte ajudava a nutrir um sujeito racional que poderia, como argumentou Friedrich Schiller em On the Aesthetic Education of Man, evitar os excessos tanto da selvageria (identitarismo, subjetivismo) quanto da barbárie (dogmatismo, objetivismo). ${ }^{2}$ Nos dois séculos desde aquele momento, testemunhamos o surgimento de alegações de que a arte pode mudar a sociedade para melhor e expressar a humanidade enquanto um projeto, e não como uma superstição fatal. As formações culturais resultantes incluem romantismo, realismo, arte pela arte, vanguardismo, mo- 
dernismo e contracultura. Apesar de suas concepções muito diferentes, o que todos esses movimentos tinham em comum era o pano de fundo do capitalismo liberal ocidental e da ideologia burguesa.

Desde o pós-modernismo, temos contado a nós mesmos uma história diferente. A história terminou e, portanto, a resistência estética ao capitalismo burguês também terminou. Mark Fisher define a sensação de que o capitalismo agora é o único sistema socioeconômico viável como "realismo capitalista". ${ }^{3}$ Poderíamos dizer que grande parte da arte que é produzida hoje é arte realista capitalista. Considerando que a maioria dos movimentos artísticos dos séculos XIX e XX eram críticos à ideologia burguesa, a arte contemporânea se encontra em uma situação estranha em relação ao legado da modernidade.

Pode-se argumentar que a condição pósmoderna levou a dois pontos de vista contrastantes em relação à democracia e à cultura. A primeira perspectiva, baseada, por exemplo, nos escritos de Claude Lefort e Chantal Mouffe, argumenta que o cadeira do poder está vazia e que a democracia é um jogo interminável de agonismo entre as diferentes formações de poder constituinte envolvidas na luta por hegemonia. ${ }^{4}$ Seria possível associar essa perspectiva a várias correntes intelectuais contemporâneas, desde as políticas identitárias e interseccionalidade à democracia radical e ao neoanarquismo. Como nenhuma dessas formações é uma grande ameaça ao capitalismo global, elas recebem um apoio razoável na Academia, na grande mídia e no mundo da arte. De acordo com Ellen Meiksins Wood, entretanto, o capitalismo não apenas se apoia no racismo e na discriminação de gênero como base para a exploração, mas também manipula as lutas contra a opressão para fins capitalistas similares. As tendências na esquerda em direção à diferença e à diversidade, ela argumenta, não apenas abriram espaços para a luta emancipatória, mas ao mesmo tempo se tornaram desculpas para uma retirada política e ameaçam funcionar como álibis para o capitalismo. ${ }^{5}$ Uma questão para o mundo da arte é, então, como combater o desvio da democracia em direção à extrema direita e, ao mesmo tempo, repensar a rejeição pós-modernista da universalidade e da luta de classes. 
BEN\&JERRY'S IS PROUD TO PRESENT

\section{Berniepalooza}

NEILYOUNG I CARDIB I CATPOWER I BILLYBRAGG I KILLERMIKE | RAGEAGAINSTTHEMACHINE I SONICYOUTH I SARAHLEEGUTHRIE I ARIANAGRANDE IZ-TRIP IROGERWATERSISIMON\& GARFUNKEL I DAVEMATTHEWS I B I GBOI I VAMP IREWEEKEND I L I LB | | OZOMALTI I JOHNLURIE I JULLIANCASSABLANCAS I LILYACHTY | JEFFTWEEDY | JACKWHITE I NORAHJONES I BONNYRAITT I DIPLO | BRADCORRIGAN I GRAHAMNASHDAVIDCROSBY I JACKSONBROWNE I REGGIEWATTS I MILEYCIRUS I REDHOTCHILIPEPPERS I NONAME I JELLOBIAFRA I ANIDIFRANCO I LONGHORNESLIM I BROTHERALI | LINDAWILLIAMS I BASSNECTAR I TYLERTHECREATOR I DISPATCH

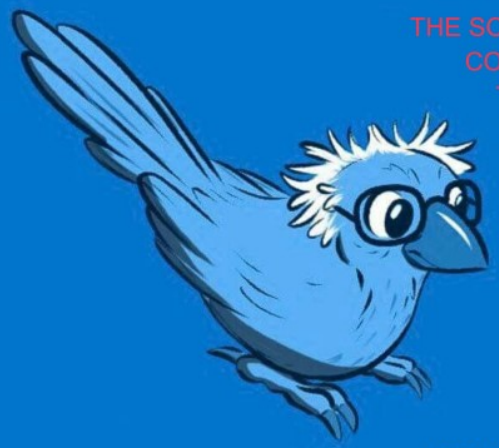

NOAM CHOMSKY

CORNEL WEST

GLENN GREENWALD MICHAEL MOORE NAOMI KLEIN ADOLPH L. REED JR. KYLE KULINSKI KEEANGA-YAMAHTTA TAYLOR KRYSTAL BALL

\#BERNIEPALOOZA \#NOTMEUS \#FEELTHEBERN \#BIGUS

Revista Poiésis, Niterói, v. 21, n. 36, p. 209-222, jul./dez. 2020. (https://doi.org/10.22409/poiesis.v21i36.43173) 
Uma perspectiva contrastante, baseada nos escritos "pós-marxistas" de pessoas como Slavoj Žižek, Alain Badiou e Franco Berardi, é que a cadeira do poder nunca está vazia, mas, ao contrário, é, e tem sido há muito tempo, ocupada pelo capitalismo global. ${ }^{6}$ As disputas por hegemonia de hoje, sejam identitárias ou nacionalistas, são de fato condicionadas e geradas pelas crises e contradições do biocapitalismo contemporâneo. Enquanto o capitalismo industrial se preocupava com a extração do excedente do trabalho por meio da extensão da jornada de trabalho, da redução de salários e da crescente velocidade da produção, o biocapitalismo compensa a perda de mais-valia buscando novas áreas de capitalização, como a educação, cultura e lazer, estendendo seu alcance à totalidade da vida social, identidade e até à nossa substância biogenética. Neste sentido, as lutas identitárias pós-modernas são uma faceta da lógica cultural do capitalismo pós-fordista.

Tomando emprestada a terminologia de Žižek, poderíamos nos referir ao primeiro ponto de vista como "culturalização da política" e o segundo como "politização da cultura". A esse respeito, pode-se dizer que o tipo de arte ativista que foi produzida no contexto de protestos antiglobalização e os movimentos das praças como Occupy Wall Street e $V$ for Vinegar representam uma politização da cultura e que, em contraste, a culturalização da política produz fenômenos como "chamamentos" e boicotes de artistas e instituições que representam valores e hierarquias sociais obsoletos. ${ }^{7}$ Ambas as variantes da política progressista dão à arte e à cultura um papel proeminente na mudança social democrática, e ambas têm consciência da função da arte nas sociedades reguladas por regimes de acumulação flexível e austeridade socioeconômica.

Ao considerar as possibilidades de politização da cultura, ficamos impressionados com a persistência do neoliberalismo, com sua lógica de mercado e regulação estatal. Como demonstrou o fracasso do referendo grego, as políticas neoliberais fazem qualquer clamor à democracia popular através da política parlamentar uma quimera um tanto enganadora. A política parece vacilar entre o neoliberalismo com uma face humana, multicultural (do tipo Barack Obama e Hillary Clinton) e o neoliberalismo com características mais autoritárias e repressivas (do tipo Donald Trump e Jair Bolsonaro). 
Após a onda de protestos associados à antiglobalização e o movimento das praças na Grécia, Espanha, Egito, Turquia, Brasil, Estados Unidos e Canadá, temos sido assolados por contramovimentos de direita associados a partidos políticos da extrema direita e com versões "contraculturais" que são chamadas de direita alternativa (alt-right). Como a teórica cultural Angela Nagle propôs corajosamente em seu livro Kill All Normies, os conservadores culturais que lutaram do lado errado nas guerras culturais das décadas de 1960 a 1990 foram substituídos por uma "vanguarda", como ela chama, de gamers adolescentes, amantes de anime, conservadores fãs de South Park, pranksters ${ }^{8}$ anti-feministas e trolls ${ }^{9}$ da Internet. ${ }^{10}$ De acordo com Nagle, o amor à transgressão por si só torna difícil conhecer a política de pessoas que preferem "a zoeira" à correção política da política dos campi. Seu único senso político é a crença de que eles são de alguma forma contra as correntes hegemônicas. Essa combinação de atitudes antissistema e confusão política ajuda a explicar o sucesso de políticos como Donald Trump e, mais recentemente, Joe $\mathrm{Bi}$ den. No entanto, a tese de Nagle vai além da direita alternativa e sugere que os aspectos progressistas da subversão contra- cultural e da ironia pós-moderna cobram o seu preço, com millennials ${ }^{11}$ confusos e precários tanto do lado esquerdo quanto do lado direito contra qualquer tipo de seriedade, assim, permitindo que desenvolvimentos genuinamente sinistros surjam. Os debates aborrecidos entre conservadorismo cultural e estudos culturais encontram a vida online, onde as pessoas hoje se sentem mais empoderadas por suas contas no Twitter e no Facebook do que por seus representantes locais.

Segundo Žižek, a governança neoliberal em breve estará causando um sofrimento incalculável. Pensa-se nos recentes furacões e incêndios florestais, bem como nas consequências da falta de preparação no contexto de pandemias globais como a COVID-19. Nos Estados Unidos, a maioria dos empregos com salários decentes está ameaçada, juntamente com a educação pública e o que resta do seguro social e do Medicare ${ }^{12}$. O Canadá, por outro lado, tem sido pressionado pelos EUA a dobrar seus gastos militares em apoio ao fortalecimento da OTAN na fronteira com a Rússia e no Mar do Sul da China. Esperemos que não enfrentemos em breve os efeitos da guerra nuclear "limitada". Žižek argumenta que, se quisermos 
resgatar o que vale a pena na democracia liberal, precisamos estabelecer uma nova solidariedade global baseada em acordos internacionais, no controle de bancos, normas ambientais, direitos dos trabalhadores, planos de saúde universais e proteção das minorias. Para que isso aconteça, ele diz, os liberais progressistas de hoje precisam se concentrar em suas próprias deficiências, assim como o capitalismo liberal fez quando enfrentou o desafio do movimento socialista internacional. ${ }^{13}$

No caso dos EUA, o argumento de Žižek é melhor exemplificado por Thomas Frank, que, em seu livro Listen, Liberal, explica que, apesar da recuperação econômica e dos avanços da produtividade desde a crise do sistema financeiro de 2008, nenhum dos benefícios foi concedido a pessoas comuns cujas vidas não têm chance de melhora nos níveis de salários e de renda. ${ }^{14} \mathrm{~A}$ reversão da trajetória estadounidense de prosperidade não pode ser compensada por mais trabalho e esforço. Enquanto isso, os proprietários do Walmart agora possuem mais riqueza do que os $40 \%$ mais pobres da população dos EUA. O argumento de Frank é que, nas últimas quatro décadas, o Partido Democrata abandonou a classe trabalhado- ra em favor do capital e dos interesses dos bilionários.

Não muito diferente de Nagle, Frank aponta como as conquistas dos direitos civis, como o casamento heteronormativo, a remoção das bandeiras confederadas e a eleição do primeiro presidente negro receberam o apoio da "América" corporativa e foram comemoradas pela grande imprensa como triunfos do Partido Democrata que ganharam o apoio dos jovens, das minorias e de profissionais de classe média. Como foi então que os mesmos democratas perderam o controle da Casa Branca, do Congresso e da Suprema Corte? É apropriado culpar a classe trabalhadora branca, como alguns fazem, especialmente quando a maior parte do apoio de Trump vem da classe média e das elites abastadas? Segundo Frank, embora os democratas tenham sido progressistas em questões de diversidade, eles não acreditam que possam fazer alguma coisa quando se trata de questões sociais importantes como a ecologia e justiça econômica. Além da hierarquia do poder econômico, os democratas são igualmente sensíveis, argumenta Frank, pela hierarquia de mérito, aprendizado e status, substituindo o "partido do povo" por um partido obcecado pelo

Marc James Léger, Democracia sem garantias. 
status profissional e pelos valores da "classe criativa" bem escolarizada que monopoliza o conhecimento. Esse profissionalismo tecnocrático, ele argumenta, não é apenas antidemocrático, pois prioriza as opiniões de especialistas, mas como ideologia política, o profissionalismo é uma "ideologia pósindustrial" que se tornou um poder de monopólio de interesse próprio. Frank argumenta que os democratas deixaram de se preocupar com os interesses dos trabalhadores e se dedicaram às preocupações da meritocracia da classe média alta. Suas teorias têm sido mais do que validadas pelos esforços coordenados do Partido Democrata para fazer tudo o que estiver ao seu alcance para impedir Bernie Sanders e seus apoiadores de vencerem a corrida pela liderança. Os neoliberais não ouviram. Em vez disso, eles orquestraram a nomeação de Joe Biden, uma marionete de Wall Street que persuadiu os estadounidenses com o boato sobre as armas de destruição em massa que deu início a chamada Guerra ao Terror.

Como, então, o mundo da arte é afetado por tais políticas neoliberais do "fim da história"? A sociologia da polarização de classes e seus efeitos colaterais direitistas não são um campo totalmente novo de pesquisa. Podemos pensar em The Salaried Masses (1930) de Siegfried Kracauer, White Collar (1951) de C. Wright Mills e Classes in Contemporary Capitalism (1973) de Nicos Poulantzas. Mais recentemente, The University in Ruins de Bill Readings alertounos para o crepúsculo da função social da educação universitária no contexto de um processo de mercantilização que indexa toda a produção de conhecimento ao produto interno bruto. ${ }^{15}$ Formas semelhantes de análise de classe têm sido aplicadas à produção cultural na era da política das indústrias criativas.

No final da década de 1970, em seu livro Distinction, o sociólogo Pierre Bourdieu delineou os diferentes gostos culturais e disposições sociais da população francesa. ${ }^{16} \mathrm{O}$ que Bourdieu definiu como habitus "pequeno-burguês" é hoje a disposição dominante de uma classe global de pessoas ativistas e criativas que não se identificam mais em termos de classe e que, ao invés disso, demonstram um compromisso "pós-político" com a escolha do estilo de vida, anti-hierarquia, anti-autoridade, o gosto pelo novo, a ética divertida e distância das forças de mercado. ${ }^{17} \mathrm{O}$ status hegemônico da dispo- 
sição pequeno-burguesa tem acompanhado as condições desreguladas do conhecimento e da produção cultural na era da precariedade e das redes sociais. ${ }^{18}$ Neste contexto, duas facções da classe pequeno-burguesa global disputam a hegemonia. Uma facção é a que Frank se refere como classe do conhecimento, à qual também poderíamos nos referir como classe criativa, em alusão aos escritos de Richard Florida. ${ }^{19} \mathrm{O}$ outro grande grupo é uma classe ativista, que poderíamos associar a novos movimentos sociais, ONGs e fóruns sociais mundiais. A função da arte no biocapitalismo atual é produzir e reproduzir as novas formas de luta não ideológica dentro das fileiras da classe pequeno-burguesa global, com suas facções ativistas e profissionais concorrentes. A suposição dessa pós-política do "fim da ideologia" é que a história da luta de classes chegou ao fim e o capitalismo liberal, com a pequena chance de alguns ajustes social-democratas, é a única opção restante. Qualquer esperança de mudança social, na minha opinião, virá de uma ruptura com essa ordem de conflito intraclasse e envolverá a totalidade do espaço social. Tal ruptura exigirá o trabalho tanto das vanguardas políticas quanto estéticas. Uma arte que rompe com as condições que a origi- nam não é uma arte de transgressão, mas uma arte de negação. ${ }^{20}$ A reflexão da arte sobre suas condições de possibilidade inclui as críticas à democracia capitalista que vieram das vanguardas artísticas e políticas. Isso inclui uma crítica da categoria de arte. Tal cultura revolucionária de vanguarda pode não ser definitivamente democrática em sua diferença do politicamente correto e em seu comunismo anti-anti-arte. Provavelmente não receberá muito apoio comercial ou institucional.

Como podemos explicar o déficit democrático no campo da produção e da recepção da arte? Boris Groys argumenta que a sensibilidade estética pós-moderna rejeita tudo o que é universal e, portanto, rejeita o comunismo. A política pós-modernista da diversidade cultural, ao contrário, é um gosto formado pelo mercado e, portanto, um gosto pelo mercado. ${ }^{21}$ Consequentemente, os projetos universais do Iluminismo e do comunismo não são mais possíveis porque são comercialmente inoperantes. No entanto, Groys argumenta, somente a política universal e a cultura universal são verdadeiramente democráticas. 
Como Alain Badiou também argumenta, todos os eventos genuínos no campo da arte e da política são universais porque a verdade é a mesma para todos. ${ }^{22}$ A teoria do evento de Badiou é um meio de resolver o enigma da multiplicidade de identidade e da universalidade de eventos genuínos. A noção de Badiou da ontologia do ser, desenvolvida de acordo com a psicanálise lacaniana e a teoria dos conjuntos, é que a subjetividade é infinitamente múltipla. Além desse nível básico de ontologia, os humanos às vezes agem em consonância com eventos que criam novas situações nos domínios da arte e da política. A verdade dos eventos exige que a sociedade vá além do relativismo do que Badiou se refere como o "materialismo democrático" de corpos e linguagens. Ele define "materialismo dialético" como o processo de subjetivação pelo qual passamos de ser meramente humanos para ser sujeitos de um evento que não depende de normas pré-existentes e causas atribuíveis - uma democracia sem garantias. 0 consequente universalismo que ele descreve não está preocupado em fazer as pazes com o status quo. No entanto, também não é dado à destruição niilista.
Um estupro, um genocídio, a superstição ou a redução da arte à vida não constituem eventos. ${ }^{23} \mathrm{O}$ acesso à universalidade exige, portanto, um passo além da definição vitimada de humanidade que é a base de grande parte da política culturalizada de hoje. Um procedimento de verdade, como o evento do comunismo ou como o evento de montagem no filme, emprega a genericidade do verdadeiro, produzindo uniformidade, igualdade e emancipação. O fascismo, por outro lado, produz diferença: a raça superior como diferença absoluta. A universalidade do comunismo tem, portanto, suas palavras-chave: luta de classes, revolução e abolição da propriedade privada. ${ }^{24} \mathrm{O}$ evento de arte de Badiou contradiz a noção que temos do materialismo histórico de que as negações da arte são, de alguma forma, também equivalentes às relações sociais efetivamente existentes no capitalismo. Somente a teoria de vanguarda do fim da arte fornece uma conceitualização adequada de uma nova subjetividade para além do biocapitalismo. Nenhuma ideologia prematura do "fim da história" é adequada à sua política de emancipação universal. 
May 2020

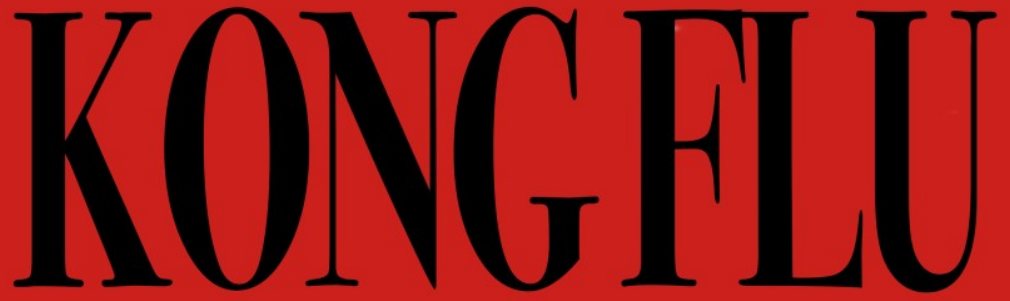

CAN DIALECTICS BREAK NEOLIBERAL HEGEMONY?

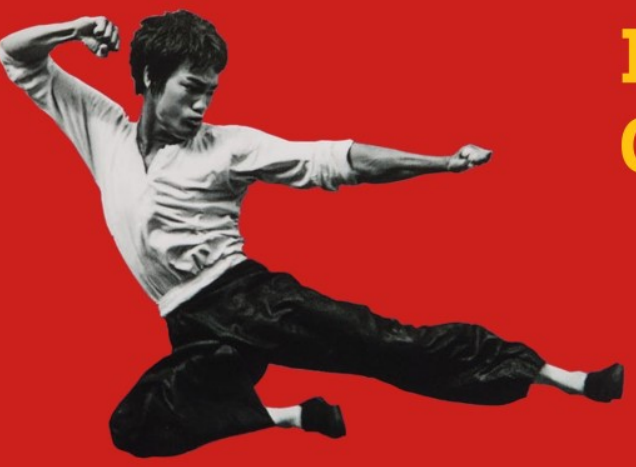

HOW PUTIN INCUBATED CORONA-19

RESTORING FAITH IN INTERNATIONAL SUPPLY CHAINS WILL REQUIRE

A GREAT AWAKENING OF PUBLIC AND PRIVATE LIFE

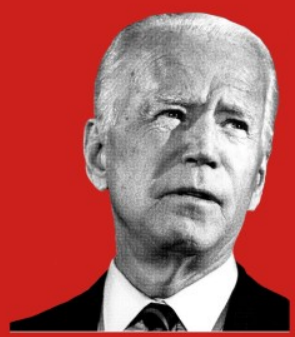

DEMS: THIS

PANDEMIC

COULD LEAD

TO SOCIALIST

REVOLUTIONS

PUT AUSTERTYY

\& MILITARISM

BACK TO WORK
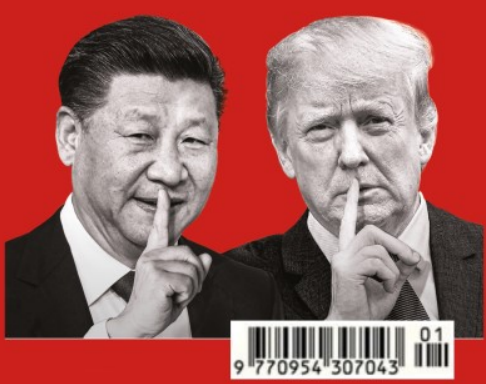


\section{Notas}

${ }^{1}$ Esta é uma versão editada do artigo publicado originalmente na revista Esse: Arts+Opinions \#92, p. 11-13, inverno 2018. Os editores da Revista Poiésis expressam seus agradecimentos ao autor, Marc James Léger, e à editora da revista esse, Sylvette Babin, pela generosa autorização para a tradução do texto para o português e sua subsequente publicação nesta edição.

${ }^{2}$ Friedrich Schiller, On the Aesthetic Education of Man, trad. Reginald Snell (Mineola, NY: Dover Publications, [1794] 1954/2004).

${ }^{3}$ Mark Fisher, Capitalist Realism: Is There No Alternative? (Winchester: O Books, 2009).

${ }^{4}$ Ver, por exemplo, Claude Lefort, Democracy and Political Theory (Minneapolis: University of Minnesota Press, 1989) e Chantal Mouffe, Artistic Activism and Agonistic Spaces, Art \& Research, v. 1, n. 2 (verão 2007), disponível em http://www.artandresearch. org.uk/v1n2/mouffe.html. Ver também minha discussão a respeito dos maus usos do trabalho de Antonio Gramsci em The Only Game in Town, por Marc James Léger em Vanguardia: Socially Engaged Art and Theory

(Manchester: Manchester University Press, 2018, p. 179-213).

${ }^{5}$ Ellen Meiksins Wood, Democracy Against Capitalism: Renewing Historical Materialism (Cambridge: Cambridge University Press, 1995, p. 238).

${ }^{6}$ Ver, por exemplo, Slavoj Žižek, Class Struggle or Postmodernism? Yes, Please! em Judith Butler, Ernesto Laclau e Slavoj Žižek, Contingency, Hegemony, Universality: Contemporary Dialogues on the Left (Londres: Verso, 2000, p. 90-135); Alain Badiou, Saint Paul: The Foundation of Universalism, trad. Ray Brassier (Stanford: Stanford University Press, [1997] 2003); LaborinArt, Running Along the Disaster: A Conversation with Franco ‘Bifo' Berardi, e-flux Journal \#56 (jun.
2014), disponível em http://www.e-flux.com/journal/ $56 / 60328 /$ running-along-the-disaster-a-conversationwith-franco-bifo-berardi/.

${ }^{7}$ Ver Yates McKee, Strike Art: Contemporary Art and the Post-Occupy Condition (Londres: Verso, 2016).

${ }^{8}$ N. do T.: Pranksters podem ser definidos como aqueles que fazem uma brincadeira que tem a intenção de ser engraçada, podendo ser somente por diversão ou com objetivo de fazer uma sátira política ou social, porém sem prejudicar ou causar danos a ninguém.

${ }^{9} \mathrm{~N}$. do T.: Internet troolls faz referência a alguém que deixa uma mensagem intencionalmente irritante ou ofensiva, no ambiente virtual da internet, com o objetivo de incomodar, de chamar a atenção ou de causar problemas.

${ }^{10}$ Angela Nagle, Kill All Normies: Online Culture Wars

(Winchester: Zero Books, 2017) eBook, 11.

${ }^{11} \mathrm{~N}$. do T.: 0 termo, geralmente empregado no plural, não encontra correspondência no uso comum da língua portuguesa. Ele é usado para designar, em inglês, pessoas nascidas nos anos 1980 ou 1990.

${ }^{12} \mathrm{~N}$. do T.: Sistema de seguro de saúde, gerenciado pelo governo dos Estados Unidos, destinado a idosos (a partir dos 65 anos) e a pessoas que se enquadrem em critérios de rendimentos determinados pelo governo.

${ }^{13}$ Slavoj Žižek, We Must Rise from the Ashes of Liberal Democracy, In These Times (3 mar. 2017), disponível em http: / /inthesetimes.com/article/19918/slavojzizek-from-the-ashes-of-liberal-democracy.

14 Thomas Frank, Listen, Liberal, or, What Ever Happened to the Party of the People? (Nova York: Metropolitan Books, 2016). 
${ }^{15}$ Bill Readings, The University in Ruins (Cambridge: Harvard University Press, 1997).

${ }^{16}$ Pierre Bourdieu, Distinction: A Social Critique of the Judgement of Taste, trad. Richard Nice (Cambridge: Harvard University Press, [1979] 1984).

${ }^{17}$ Ver Welcome to the Cultural Goodwill Revolution por Marc James Léger em Brave New Avant Garde: Essays on Contemporary Art and Politics (Winchester: Zero Books, 2012, p. 82-99). Ver também Tony Bennett, Habitus Clivé: Aesthetics and Politics in the Work of Pierre Bourdieu, New Literary History, v. 38, n. 1, p. 201-228, 2007.

${ }^{18}$ Ver, por exemplo, Lane Relyea, Your Everyday Art World (Cambridge: The MIT Press, 2013).

${ }^{19}$ Richard Florida, The Rise of the Creative Class... And How It's Transforming Work, Leisure, Community \& Everyday Life (Nova York: Basic Books, 2002).

20 John Roberts, Art and Its Negations, Third Text, v. 24, n. 3, p. 290, maio 2010.

${ }^{21}$ Boris Groys, Beyond Diversity: Cultural Studies and Its Post-Communist Other, em Art Power (Cambridge: The MIT Press, 2008, p. 150).

22 Para uma sinopse da teoria do evento de Badiou e das quatro ordens do procedimento da verdade (Amor, arte, política, ciência), ver Alain Badiou, Philosophy and the Event (with Fabien Tarby), trad. Louise Burchill (Cambridge: Polity Press, [2010] 2013).

${ }^{23}$ Para uma crítica da base supersticiosa da política racial, ver Racecraft: The Soul of Inequality in American Life (Londres: Verso, 2014) por Karen E. Fields e Barbara J. Fields. Um exemplo da redução supersticiosa da arte à vida é a teoria da performance de Peggy Phelan em Unmarked: The Politics of Performance (Londres: Routledge, 1993).
${ }^{24}$ Ver Alain Badiou, Greece and the Reinvention of Politics, trad. David Broder (Londres: Verso, 2018).

Marc James Léger, Democracia sem garantias. 